\title{
Lim Mineralization Protein 3 Induces the Osteogenic Differentiation of Human Amniotic Fluid Stromal Cells through Kruppel-Like Factor-4 Downregulation and Further Bone-Specific Gene Expression
}

\author{
Marta Barba, ${ }^{1}$ Filomena Pirozzi, ${ }^{2}$ Nathalie Saulnier, ${ }^{3,4}$ Tiziana Vitali, ${ }^{2}$ Maria Teresa Natale, ${ }^{2}$ \\ Giandomenico Logroscino, ${ }^{5}$ Paul D. Robbins, ${ }^{6,7}$ Andrea Gambotto, ${ }^{8}$ Giovanni Neri, ${ }^{2}$ \\ Fabrizio Michetti, ${ }^{1,9}$ Enrico Pola, ${ }^{5}$ and Wanda Lattanzi ${ }^{1,9}$ \\ ${ }^{1}$ Institute of Anatomy and Cell Biology, Università Cattolica del Sacro Cuore, L.go F. Vito 1, 00168 Rome, Italy \\ ${ }^{2}$ Institute of Medical Genetics, Università Cattolica del Sacro Cuore, L.go F. Vito 1, 00168 Rome, Italy \\ ${ }^{3}$ Institut National de la Santé et de la Recherche Medicale, 101 Rue de Tolbiac, 75654 Paris Cedex 13, France \\ ${ }^{4}$ Institut Cochin, Université Paris Descartes, Sorbonne Paris Descartes, CNRS (UMR 8104), Paris, France \\ ${ }^{5}$ Department of Orthopaedics, Università Cattolica del Sacro Cuore, L.go Gemelli 8, 00168 Rome, Italy \\ ${ }^{6}$ Department of Microbiology and Molecular Genetics, University of Pittsburgh School of Medicine, \\ 427 Bridgeside Point II, 450 Technology Drive, Pittsburgh, PA 15219, USA \\ ${ }^{7}$ Department of Metabolism and Aging, The Scripps Research Institute-Florida, 130 Scripps Way, \\ Jupiter, Florida 33458, USA \\ ${ }^{8}$ Department of Surgery, Rangos Research Center, University of Pittsburgh 530 45th Street, Pittsburgh, PA 15201, USA \\ ${ }^{9}$ Latium Musculoskeletal Tissue Bank, L.go F. Vito 1, Rome, Italy
}

Correspondence should be addressed to Wanda Lattanzi, wanda.lattanzi@rm.unicatt.it

Received 23 January 2012; Revised 19 April 2012; Accepted 30 April 2012

Academic Editor: Thomas Lufkin

Copyright () 2012 Marta Barba et al. This is an open access article distributed under the Creative Commons Attribution License, which permits unrestricted use, distribution, and reproduction in any medium, provided the original work is properly cited.

\begin{abstract}
Multipotent mesenchymal stem cells with extensive self-renewal properties can be easily isolated and rapidly expanded in culture from small volumes of amniotic fluid. These cells, namely, amniotic fluid-stromal cells (AFSCs), can be regarded as an attractive source for tissue engineering purposes, being phenotypically and genetically stable, plus overcoming all the safety and ethical issues related to the use of embryonic/fetal cells. LMP3 is a novel osteoinductive molecule acting upstream to the main osteogenic pathways. This study is aimed at delineating the basic molecular events underlying LMP3-induced osteogenesis, using AFSCs as a cellular model to focus on the molecular features underlying the multipotency/differentiation switch. For this purpose, AFSCs were isolated and characterized in vitro and transfected with a defective adenoviral vector expressing the human LMP3. LMP3 induced the successful osteogenic differentiation of AFSC by inducing the expression of osteogenic markers and osteospecific transcription factors. Moreover, LMP3 induced an early repression of the kruppel-like factor-4, implicated in MSC stemness maintenance. KLF4 repression was released upon LMP3 silencing, indicating that this event could be reasonably considered among the basic molecular events that govern the proliferation/differentiation switch during LMP3-induced osteogenic differentiation of AFSC.
\end{abstract}

\section{Introduction}

Cell-based strategies are widely used for tissue engineering purposes, that is, to achieve the replacement, repair, and restoration of tissue and organ functions. Somatic stem cells, especially mesenchymal stromal cells (MSCs), represent the most valuable resource to this aim, being mainly used in orthopedics applications $[1,2]$. MSCs, originally isolated from bone marrow, are multipotent cells, residing in the connective stroma of different adult tissues and solid organs, and capable to differentiate toward multiple mesodermal lineages [3]. MSCs can be indeed isolated from different adult tissues sources, including fat, skeletal muscle and skin [3-8]. Beside adult tissues, more recently MSC have been isolated from 
fetal and perinatal fluids and tissues, including umbilical cord (UC), chorionic villi (CV), and amniotic fluid (AF) [9-11]. Particularly, amniotic fluid stromal cells (AFSCs) can be regarded as attractive pluripotent stem cells, due to the ease of isolation from small volumes of $\mathrm{AF}$, their rapid expansion in culture and their capability of extensive selfrenewal [11-13]. In addition, AFSCs appear phenotypically and genetically stable after in vitro expansion, overcoming all the safety issues related to the use of embryonic/fetal cells [14]. The surface marker profile of AFSC suggests that they represent an intermediate stage between embryonic stem cells and adult MSC $[11,15]$. In fact, AFSC retain the ability to differentiate into cells of all three embryonic germ layers along with higher growth kinetics than adult MSC $[3,10,13,16]$. These features makes AFSCs unique among somatic stem cells and suggests their possibile application in translational medicine, by-passing the common ethical issues associated to embryonic stem cells.

Among the wide range of tested clinical applications of AFSCs [17], their osteogenic potential has been particularly investigated as a potentially relevant property, in the light of the attractive results obtained in animal models of skeletal regeneration $([18-20])$. The complete network of molecular signals involved in the osteogenic commitment of MSCs has been partially defined. We have previously demonstrated that the Kruppel-like factor family genes, coding for DNA-binding proteins, play a crucial role in maintaining MSC stemness and self-renewal properties by transcription regulation and are progressively repressed during MSC differentiation [21].

The LIM mineralization protein (LMP) is an intracellular positive regulator of osteoblast differentiation that is able to induce the osteogenic differentiation of MSC, by activating the expression of genes that govern the balance between cell proliferation/differentiation and are involved in skeletal tissue development $[22,23]$. LMP was originally isolated from the rat calvaria and is present in three alternatively spliced transcript variants, namely, LMP-1, -2, and -3, in humans (GenBank accession numbers: AAK30567.1; AAK30568.1, AAK30569.1, respectively, [24, 25]. The first two transcript variants, LMP1 and LMP2, encoding the full-length and intermediate protein isoforms, respectively, contain both PDZ and LIM conserved domains in their structure. LMP3 encode a truncated isoform and represent the shortest variant [26]. Both LMP1 and LMP3 are osteogenic and could represent promising molecular tools for bone tissue-engineering applications, as recent studies demonstrated that they act upstream to the main osteogenic pathways $[1,22,23,27]$. In particular, the most functionally relevant molecular interactions involved in the LMP1 osteogenic properties have been clarified in vitro, while the LMP3-related osteogenic signalling is still poorly understood.

The aim of this study was to assess the capability of LMP3 to induce the osteogenic differentiation of AFSCs, and to characterize the molecular events associated to this process, focusing on the molecular features underlying the multipotency/differentiation switch.

\section{Materials and Methods}

2.1. Cell Isolation and Culture. Amniotic fluid samples were obtained by amniocentesis performed between 16 and 20 weeks of gestation for fetal karyotyping. Patients were enrolled in the study upon signing a written informed consent. All procedures employed in this study have been approved by the Ethical Committee of the Catholic University of Rome, Italy (protocol number P552 (A.779/CE2007).

AFSCs were isolated from the diagnostic specimens using a two-step culture protocol, saving the amniocytes needed for chromosome analysis [3, 28]. Briefly, nonadherent cells were collected by centrifugation from the culture medium saved from amniocytes after 7 days of primary culture. Cells were then plated in T25 tissue culture flasks at a seeding density of $10^{5} \mathrm{cells} / \mathrm{cm}^{2}$, using the Mesenchymal Stem Cell Medium (MSCGM) (Lonza, Basel, Switzerland), and incubated overnight in a humidified incubator at $37^{\circ} \mathrm{C}$ and $5 \%$ $\mathrm{CO}_{2}$. The following day, the medium was replaced to remove nonadherent cells. Upon reaching $80 \%$ confluence, cells were detached with trypsin/EDTA and further expanded. The specific surface antigens of MSCs expressed on AFSC (at culture passage 4 to 5 ) were investigated by flow cytometry analysis, as previously described [3].

2.2. Adenoviral-Mediated Cell Transduction. Defective adenoviral vectors carrying the LMP-3 gene (AdLMP-3) were constructed as previously described [23]. Subconfluent AFSCs were transduced within the 3 rd culture passage with $100 \mathrm{pfu} / \mathrm{cell}$ of AdLMP-3 vector. Mock-transfected cells, that is, cells infected with an empty adenoviral vector (the viral vector backbone, termed Ad 45 ), served as negative transduction controls. Transduction efficiency was evaluated by means of RT-PCR as already described elsewhere [1]. Adtransduced cells were then used in time-course experiments aimed at analyzing the expression of selected genes and studying the morphological modifications induced by LMP3 overexpression.

2.3. In-Vitro Mineralization Assay. To evaluate the occurrence of osteogenic commitment and differentiation of cells upon LMP3 overexpression, AFSCs were alternatively transfected with either AdLMP-3 or Ad 45 . AFSCs cultured in an osteogenic medium (OM, see [3] for protocol details) served as positive controls for in vitro differentiation and qPCR. Osteogenic differentiation was assessed after 2 weeks by alizarin red staining, as previously described [3].

2.4. RNA Isolation. The total RNA was isolated from both AdLMP3- amd AdT5-transduced AFSCs, at 1, 2, 4, and 7 days post-transduction, and from positive control cells following 2 and 7 days of osteogenic induction, using the RNeasy mini kit (Qiagen, Hilden, Germany), according to the manufacturer's suggested procedures. An additional oncolumn DNase incubation step was performed, allowing the selective removal of genomic DNA during the isolation process. RNA was quantified using a UV spectrophotometer and RNA quality and integrity were assessed Agilent 2100 
Bioanalyzer (Agilent, Santa Clara, CA, USA). One microgram of RNA was reverse transcribed into cDNA using the Superscript III (Invitrogen, Carlsbad, CA, USA).

2.5. Gene Expression Analysis. In order to clarify the molecular events underlying the LMP3-mediated AFSC differentiation, we have selected downstream acting genes involved in the differentiation process and analyzed their expression using quantitative real time PCR. In particular, we have focused on the osteospecific transcription factors, Runtrelated transcription factor 2 (RUNX2) and Osterix (OSX), and on the osteospecific genes bone morphogenetic protein 2 (BMP2), Osteocalcin (OC), and Osteopontin (OP). In addition, we have analyzed the expression of the SWI/SNFrelated, matrix associated, actin-dependent regulator of chromatin, C2 (SMARCC2). This gene encodes a protein member of the chromatin remodeling complex, which was involved in the osteogenic commitment of MSCs [29] and was selected based on previous data suggesting that the LMP3 could directly induce its expression in MSCs (Lattanzi et al., unpublished observation). In addition, in order to assess if LMP3 could alter the molecular control of stem cell self-renewal and maintenance, we have analyzed the expression of the Kruppel-like factor genes KLF-2 and KLF-4 $[21,30,31]$.

Gene expression was analysed in transduced and control cells 1, 2, 4, and 7 days after adenoviral transduction, using quantitative real-time PCR. The assays were carried out in triplicate using Power SYBR Green PCR Master Mix (Applied Biosystems, Foster city, CA, USA), on a StepOne instrument (Applied Biosystems, Foster city, CA, USA). Thermocycling conditions were as follows: an initial denaturation step at $95^{\circ} \mathrm{C}$ for $20 \mathrm{sec}$ followed by 40 cycles at $95^{\circ} \mathrm{C}$ for $1 \mathrm{sec}$ and $60^{\circ} \mathrm{C}$ for $20 \mathrm{sec}$ (annealing and extension). Primer sequences were designed using the Primer 3 software (http://frodo.wi.mit.edu/primer3/) and reported in Table 1. The $2^{-\Delta \Delta C t}$ method [32] was applied to calculate fold differences (fold change, FC) in gene expression, using the gene Actin-beta (B-ACT) as the housekeeping reference for data normalization. PCR products were subjected to melting curve analysis to rule out the synthesis of unspecific products.

2.6. LMP Transient Silencing. In order to clarify the influence of LMP on KLF-2 and -4 transcriptional modulation, LMP expression was silenced in AFSCs using a specific custom-designed double-strand small interfering RNA (siRNA) construct (QIAGEN, Hilden, Germany). The sequence of the anti-LMP siRNA construct was as follows: 5'-ATGCGGGTAGCCTCACACACA-3', aligning on LMP gene sequence from base position 170 to 190 . For the silencing assay, AFSCs were plated in 24 well plates at a density of $2 \times 10^{4}$ cells/well and incubated under standard growth conditions. On next day, cells were transfected with LMP-siRNA construct, complexed with Lipofectamine RNAiMAX transfection reagent (Invitrogen, Carlsbad, CA, USA), according to the manifacturer's suggested procedure. Briefly, $0.5 \mu \mathrm{g}$ of siRNA construct were diluted in
TABLE 1: Sequences of oligonucleotide primer used in qPCR.

\begin{tabular}{|c|c|c|}
\hline Gene symbol & Sense* & Sequence \\
\hline \multirow{2}{*}{ B-ACT } & Fw & 5' $^{\prime}$ TCGTGCGTGACATTAAGGAG-3' \\
\hline & $\mathrm{Rv}$ & 5'-CCATCTCTTGCTCGAAGTCC-3' \\
\hline \multirow{2}{*}{ BMP2 } & Fw & 5'-CGTGTCCCCGCGTGCTTCTT-3' \\
\hline & $\operatorname{Rv}$ & 5'-CGGCCACCATGGTCGACCTT-3' \\
\hline \multirow{2}{*}{ KLF2 } & Fw & 5'-GGCTTGTGATGCCTTGTGA-3' \\
\hline & $\mathrm{Rv}$ & 5'-TGCCCACCTGTCTCTCTATGT-3' \\
\hline \multirow{2}{*}{ KLF4 } & $\mathrm{Fw}$ & 5'-GACCACCTCGCCTTACACAT-3' \\
\hline & $\mathrm{Rv}$ & $5^{\prime}$-CCCCCAACTCACGGATATAA-3' \\
\hline \multirow{2}{*}{ LMP } & Fw & 5'-AGCATCGATGGCGAGAAT-3' \\
\hline & $\mathrm{Rv}$ & 5'-CCGGATCTTGTTCTGAGCTT-3' \\
\hline \multirow{2}{*}{$\mathrm{OC}$} & Fw & 5'-GACTGTGACGAGTTGGCTGA-3' \\
\hline & $\mathrm{Rv}$ & 5'-AGCAGAGCGACACCCTAGAC-3' \\
\hline \multirow{2}{*}{$\mathrm{OP}$} & Fw & 5'-TGAAACGAGTCAGCTGGATG- 3' \\
\hline & $\mathrm{Rv}$ & 5'-GCTCTCATCATTGGCTTTCC-3' \\
\hline \multirow{2}{*}{ OSX } & Fw & 5'-TAGACACCATGACCCCATCA-3' \\
\hline & $\operatorname{Rv}$ & $5^{\prime}$-CATGGCAACAGGGGATTAAC-3' \\
\hline \multirow{2}{*}{ RunX2 } & Fw & 5'-GATGTGCCTAGGCGCATT-3' \\
\hline & $\mathrm{Rv}$ & 5'-AAAAGGGCCCAGTTCTGA-3' \\
\hline \multirow{2}{*}{ SMARCC2 } & Fw & 5'-CAGACATCTCTCССССТСАС-3' \\
\hline & $\mathrm{Rv}$ & 5'-CTGGAACCGTGATGTCCAC-3' \\
\hline
\end{tabular}

* : Fw: forward (left) primer; Rv: reverse (right) primer.

culture medium, thereafter, 1/10 volume of Lipofectamine RNAiMAX was added to the diluted siRNA and incubated for 10-15 minutes at room temperature. The complexes were diluted in $700 \mu \mathrm{L}$ of fresh culture medium and added to adherent cells. AFSCs transfected with a cocktail of negative control siRNA constructs (AllStars Negative Control siRNA, Qiagen) and cells treated with transfection reagent alone served as gene silencing sham and scramble controls, respectively. All experiments were carried out in triplicate in order to test the reproducibility.

The silencing efficiency of siRNA construct was evaluated by quantifying the expression of LMP gene in qPCR (see Section 2.5) 24 and 48 hours following cell transfection. The expression of KLF genes was also analyzed at the same time points.

2.7. Detection of miR143/145. In order to investigate the relation between TGF $\beta-1$ and KLF4 during the LMP3mediated osteogenic commitment, the expression levels of miR143/145 were analyzed in AdLMP3 transduced AFSCs, using untransduced cells and Ad $\Psi 5$ mock-transduced cells as controls.

For this purpose, total RNA was isolated 24 and 48 hours after transfection with Ad-LMP3 and Ad- $\Psi 5$, using the mirVana miRNA Isolation Kit (Ambion, Austin, TX, USA), following the manifacturer's suggested procedure for small RNAs enrichment. RNA was quantified using a UV spectrophotometer. $0.5 \mu \mathrm{g}$ of RNA was then reverse transcribed using the miScript Reverse Transcription Kit (QIAGEN). 


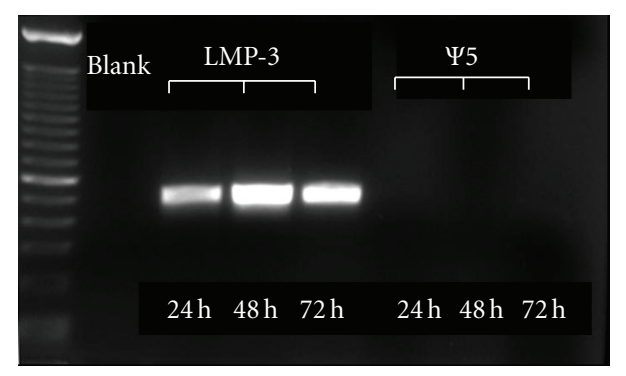

FIgURE 1: Transduction efficiency. RT-PCR showing transgenic LMP-3 expression (visible bands) up to 72 hours after cell transduction. No transgene expression can be detected in the control cells transduced with Ad $\Psi 5$.

The expression levels of miR143 and miR145 were analyzed using the miScript SYBR Green PCR Kit and miScript Primer Assays (QIAGEN, Hilden, Germany). Six control miRNA, included in the miScript PCR Control Set (QIAGEN), were amplified in real time PCR, as reference controls for data normalization. The real-time PCR reaction was carried out on the StepOne instrument (Applied Biosystems, Foster city, CA, USA), using the following thermocycling conditions: an initial activation step at $95^{\circ} \mathrm{C}$ for $15 \mathrm{~min}$ followed by 40 cycles at $94^{\circ} \mathrm{C}$ for $15 \mathrm{sec}, 55^{\circ} \mathrm{C}$ for $30 \mathrm{sec}$, and $70^{\circ} \mathrm{C}$ for $30 \mathrm{sec}$ (denaturation, annealing and extension). The $2^{-\Delta \Delta C t}$ method [32] was applied to calculate fold differences in gene expression as previously described (see Section 2.5). PCR products were subjected to melting curve analysis to rule out the synthesis of unspecific products.

\section{Results}

3.1. Isolation and Characterization of AFMSCs. Adherent cells were efficiently isolated from $\mathrm{AF}$ as soon as 2-to5 days after sample plating. The primary cellular population was heterogeneous, with elongated thin cells and flat rounded cells. Upon the first passage, all cells displayed a homogeneous adherent fibroblast-like morphology, being bipolar, spindle-shaped cells. The cells exhibited a homogenous "mesenchymal" immunophenotype: CD73+, CD90+, CD133+, cKit-.

3.2. hLMP-3 Gene Transfer Induces Osteogenic Differentiation of AFSCs In Vitro. The transduction efficiency was evaluated by means of RT-PCR to measure the transgenic LMP3 expression, using sequence-specific oligonucleotide primers. An intense PCR band of the expected size was observed at each tested time point in cells transduced with AdLMP3, indicating an efficient and stable transgene expression (Figure 1).

Alizarin staining was used to assess the osteogenic differentiation in vitro in AFSC overexpressing LMP3 compared to mock-transduced cells. Two weeks after AdLMP3 transduction, AFSC produced a diffuse red-stained mineralized matrix, as demonstrated by alizarin red staining (Figure 2(a)). Cells cultured in OM displayed a comparable degree of matrix mineralization in vitro (data not shown). Conversely, no evident signs of osteogenic differentiation were observed in mock transduced cells at the same tested time point (Figure 2(b)).

3.3. LMP-3 Induces the Osteogenic Differentiation of AFSCs by Inactivation of KLF Genes and Further Upregulation of Osteospecific Transcription Factors and Bone Marker Genes. In order to investigate the molecular effects of LMP3mediated bone induction, we examined the expression level of genes associated with stemness maintenance and osteoblastic reprogramming. The analysis revealed that LMP-3 induced a significant and time-related upregulation of osteospecific markers. In particular, the level of BMP2, increased 2.5 folds $(P<0.05)$ and more than 10 folds $(P<$ 0.05) in Ad-LMP3 transduced compared to Ad $\Psi 5$-treated cells, at day 4 and 7 after transduction, respectively. No significant modulation of BMP2 expression was observed at the earliest tested time points (day 1 and day 2; Figure 3(a)). Interestingly, the expression of BMP2 in cells treated for 7 days with the OM (FC: $4.9 ; P<0.05$ ) was lower than that induced by LMP3 (FC: $10.9 ; P<0.05$ ). No significant modulation of BMP2 expression was observed in cells cultured in $\mathrm{OM}$ at the earliest time points (Figure 3(a)). RunX2 was significantly $(P<0.05)$ upregulated in both OM-treated and LMP3-overexpressing cells, compared to control mocktransfected ones, from day 2 on. Conversely, no signficant modulation was observed at day 1 (Figure 3(b)). Particularly, at day 7, also in this case, a higher upregulation (FC: 9.8; $P<0.05)$ was observed at day 7 in LMP3-transfected cells, compared to OM-treated cells (FC: $6 ; P<0.05$; Figure 3(b)). Also, the SMARCC2 gene resulted significantly upregulated from day 2 on, in both OM-treated cells and AdLMP-3 overexpressing ones (Figure 3(c)). In particular, the increase in SMARCC2 gene expression showed a time-related trend in the AdLMP-3 group and reached the highest value $(F C>$ 20; $P<0.05$ Figure 3(c)) at day 7, when it was 4 -fold higher than in the OM group (Figure $3(\mathrm{c})$ ). The OC gene expression did not vary at either day 1 or day 2 , in any experimental group while increased significantly in AdLMP3-transduced cells at day 4 (FC: $2.2, P<0.05$ ) and day 7 (FC: 5.4, $P<0.05$; Figure 3(d)). Interestingly, no significant modulation in OC expression was induced in cells induced for 7 days in OM (Figure 3(d)). The transcription factor OSX was significantly upregulated, from day 2 on, in all treatment groups compared to Ad $\Psi 5$-treated cells, but displayed a different trend of gene expression, with higher fold changes in the OM-treated than in the LMP3-overexpressing groups, at all tested time points (Figure 3(e)). Finally, the OP gene resulted significantly upregulated exclusively at day 7 (FC: $4.4 ; P<0.05)$ in AFSCs transduced with AdLMP-3 (Figure 3(f)).

LMP-3 overexpression in AFSCs was able to modulate the expression of the Kruppel-like factors (KLF) genes. In particular, a slight (less than $40 \%$ decrease) but significant downregulation of both KLF4 (FC: $0.63 ; P<0.05$ ) and KLF2 (FC: $0.68 ; P<0.05$ ) was observed as early as 24 hours post-transduction. Thereafter, a higher fold change 


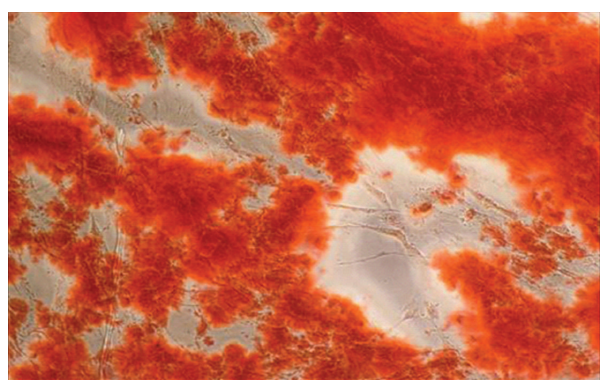

(a)

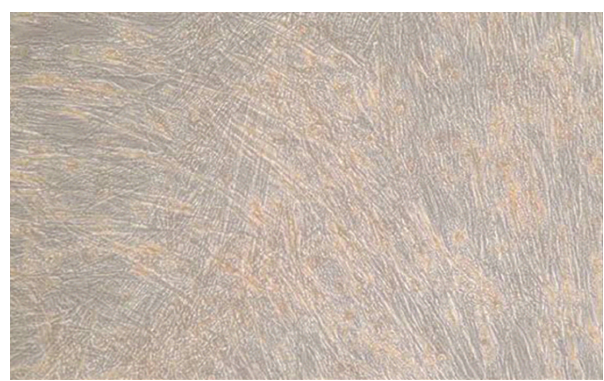

(b)

FIgURE 2: Osteogenic differentiation in vitro. Alizarin Red staining performed 2 weeks after cell transduction, showing a red-colored mineralized matrix in treated cells ((a) AdLMP-3) and negative staining in control cells ((b) Ad 45$)$.

decrease of KLF genes' expression was observed in AFSCs 2, 4, and 7 days after AdLMP3 transduction (Figure 4(a)). In particular, KLF4 expression was reduced by more than $80 \%$ in both the day 2 and the day 4 groups (FC: 0.22 and 0.23 , resp.; Figure 4(a)). A lesser extent of gene downregulation (FC: 0.59 , i.e., around $40 \%$ decrease) was then observed after 7 days. Conversely, the expression of KLF2 showed a time-related trend as its expression levels decreased gradually throughout the time course (Figure 4(a)).

3.4. LMP Silencing Induces KLF4 Upregulation. In order to verify the direct regulatory effects of LMP on KLF-2 and -4 , during the activation of the osteogenic cascade, the expression of LMP gene has been transiently inhibited in AFSCs. LMP silencing was efficient as gene expression was significantly reduced by 55\% (FC: 0.45 ) and 70\% (FC: $0.26) 24$ and 48 hours, respectively, after siRNA transfection (Figure 5(a)). The expression levels of KLF genes in LMPsilenced AFSC was transiently modulated 24 hours after LMP silencing. In particular, only the expression of KLF4 was significantly (FC: $1.58 ; P<0.05$ ) upregulated in AFSCs, while no significant change in KLF2 expression was observed (Figure 5(b)). Thereafter, expression of both KLF genes was not signficantly modified 48 hours after siRNA treatment compared to controls (data not shown).

\subsection{LMP3 Overexpression Does Not Induce the miR-143/145} Signaling. In order to verify the possible involvement of the miR-143/145 cluster activation, in the LMP3-mediated KLF4 repression, we have analyzed the expression of the two microRNA in Ad-LMP3 transduced cells, 24 and 48 hours post-transduction, using untransduced and Ad $\Psi 5$ transduced cells as controls. Our results showed that miR145 was undetectable in AFSC in all experimental groups up to 48 hours posttransfection. miR-143 was weakly expressed in all experimental conditions only at 48 hours, but no significant differential expression was observed between AdLMP3-treated cells and controls (Figure 4(b)).

\section{Discussion}

Since their original isolation from rat calvarial bone in 1998 [24], lim mineralization proteins (LMPs) have been employed to induce bone formation/healing in diverse animal models along with the osteogenic differentiation of mesoderm-derived cell types in vitro $[1,2,23,25$, 33-39]. Three alternative transcript variants are spliced from the same human gene (PDZ and LIM domain 7 (enigma), PDLIM7) giving rise to three protein isoforms, namely, LMP1, LMP2, and LMP3 (Figure 6(a)). Although the proteins are named after the presence of LIM conserved domains, these are present in only LMP1 and LMP2 isoforms; while the PDZ domain is present in all the three variants [26]. LIM domains are supposed not to be required for the osteogenic properties of LMP, considering that the osteogenic properties have been demonstrated only for LMP1 and LMP3 [26, 27]. The nonconserved region of the human LMP1 protein is represented by a 300 -aminoacid sequence (Figure 6(a)). This domain is only partially retained in LMP3, due to the alternative splicing process that causes the out-of-frame insertion of $17 \mathrm{bp}$ causing the introduction of a premature stop codon [23]. The resulting protein shares the first 133 aminoacids with LMP1, while is different in the C-terminus. The full-length isoform (LMP1, Figure 6(a)) is known to induce the expression of BMP and reinforce the osteogenic effect of exogenous BMPs during ectopic bone formation $[35,39])$. LMP3 has been shown to induce ectopic bone formation in mice, following either direct vectormediated gene transfer or using cell-based delivery, along with efficient bone healing in a rat mandibular bone defect model [1, 2, 23]. The molecular mechanisms underlying LMP3 function have been partially elucidated, by analyzing the consequences of transgenic expression in rodent cells, including calvarial osteoblasts, murine preosteoblasts and dermal fibroblasts $[1,23]$. These studies allowed demonstrating that the molecular signaling initiated by LMP3 tends to overlap with and amplify the BMP2-induced osteogenic cascade, through the direct upregulation of both BMP2 and its bone-specific target genes $[23,26]$. We have recently shown that the early phases of the molecular signaling induced by LMP3 in human bone marrow-MSCs involve the activation of the transforming growth factor $\beta 1$ pathway, leading to the regulation of cell proliferation and the induction of muscular-skeletal tissue differentiation [22]. Taken together, these data could suggest that LMP3 acts upstream to the main osteogenic developmental signaling pathways. 


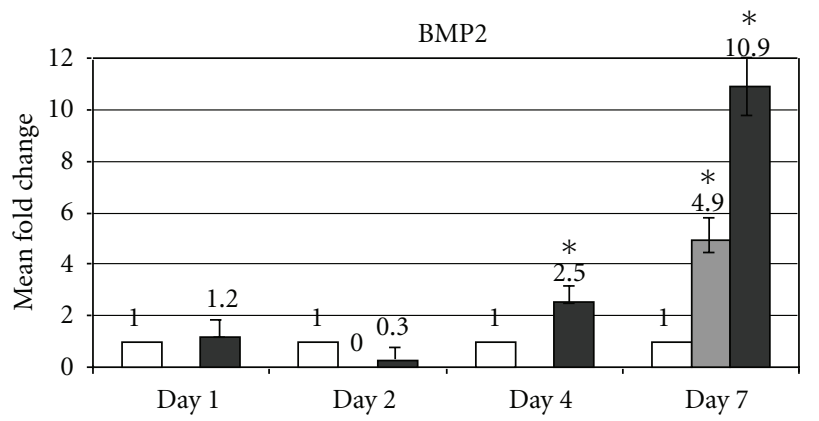

(a)

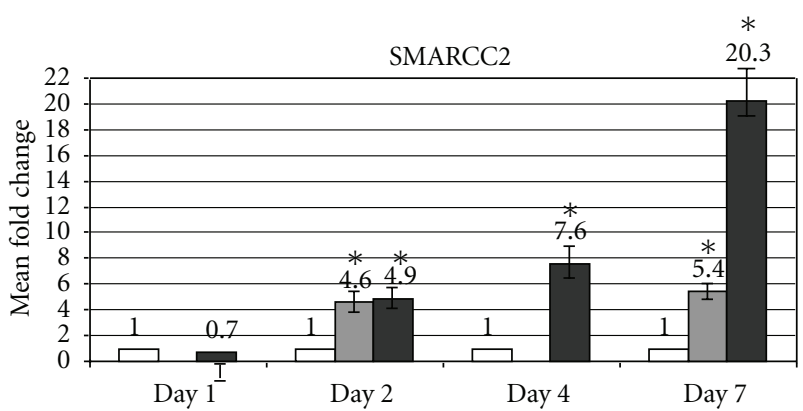

(c)

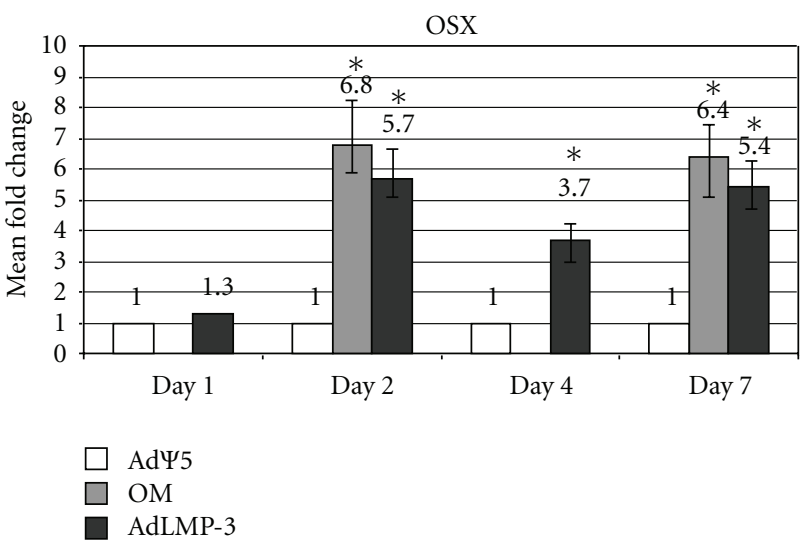

(e)

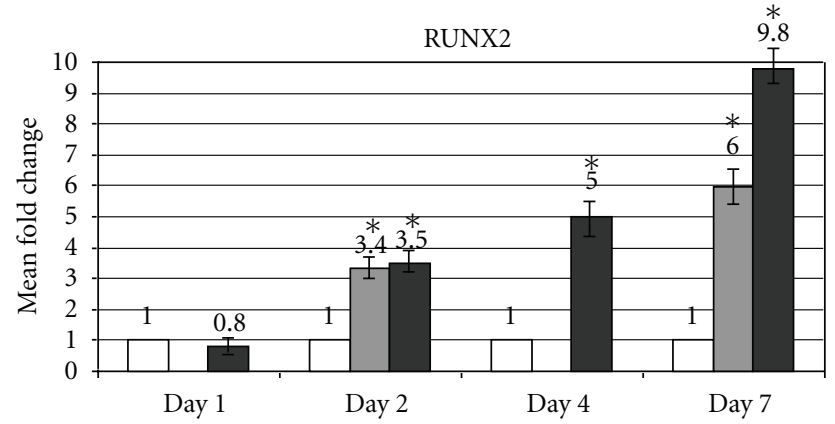

(b)

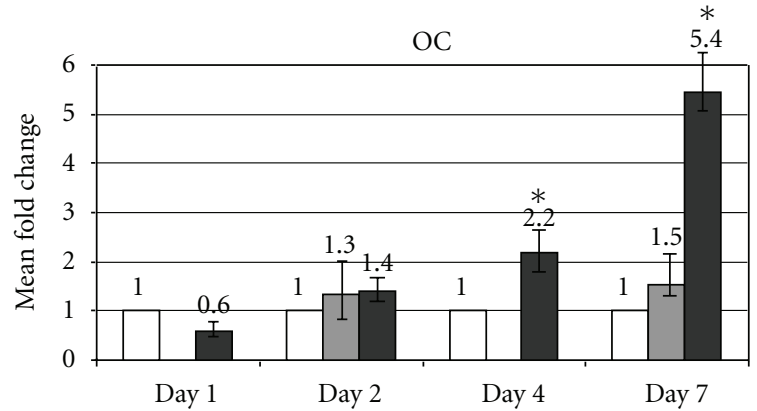

(d)

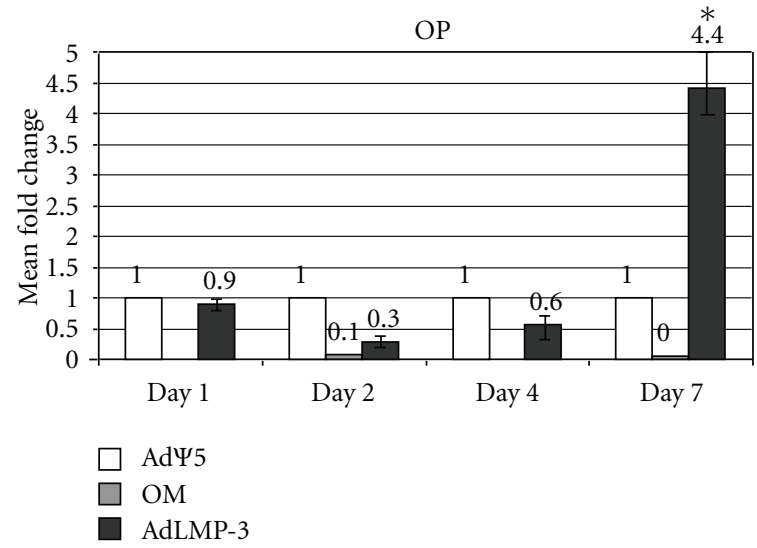

(f)

Figure 3: qPCR gene expression analysis. The graphic represents the expression levels of osteospecific gene ((a) BMP2; (b) RunX2; (c)

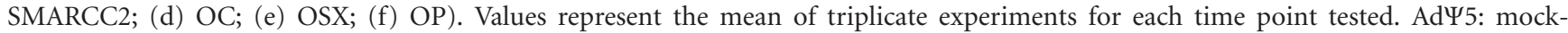
transduced control cells; AdLMP-3: treated cells; OM: cells cultivated in osteogenic medium as positive controls; d: days after cell transduction (4d-time point was not assessed in OM-cells); ${ }^{*}$ : statistical significance, $P<0.05$. Fold change was calculated according to the $2^{-\Delta \Delta C t}$ method.

In this study, we have further demonstrated that LMP3 can induce the efficient osteogenic differentiation of mesenchymal cells isolated from amniotic fluid (AFSCs). Along with other fetal tissues' derived MSCs, AFSCs display more "undifferentiated" features [3]. Recent data have indicated that induced pluripotent stem cells (iPS) are more efficiently generated from AF-derived cells rather than from human somatic cells [40]. Thus, this cell type could represent a suitable in vitro model for characterizing the basic molecular events associated to the LMP-induced osteogenic cell differentiation program $[3,11-13]$. Our results demonstrated that in AFSCs LMP3 induces a significant and early transcriptional activation of SMARCC2, along with BMP2, OC, OP, and the bone-specific transcription factors RUNX2 (CBFA1) and OSX. SMARCC2 encodes a poorly characterized member of the SWI/SNF chromatin remodeling complex necessary for the osteogenic differentiation of mesenchymal cells trough the BMP2/RunX2 pathway [29]. The effects of LMP3 on BMP2, RUNX2, and SMARCC2 gene expression was even stronger than those induced by the 


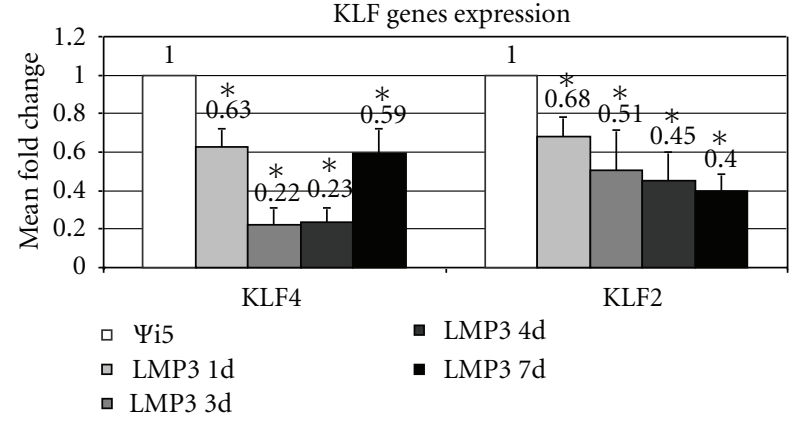

(a)

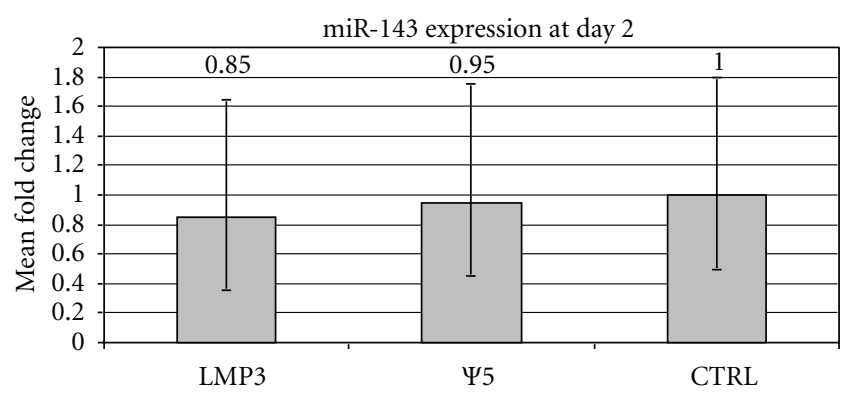

(b)

Figure 4: KLF genes expression analysis. Values represent the mean of triplicate experiments for each time point tested, namely, 2, 4, and 7 days after AdLMP3-mediated cell transduction; $\Psi 5$ : control sample represented by mock-transduced cells. Fold change was calculated according to the $2^{-\Delta \Delta C t}$ method. ${ }^{*}$ : statistical significance $(P<0.05)$.

standard osteogenic induction in AFSC cultures. Based on previous observations, it could be speculated that the overexpression of LMP3 gene tends to amplify the downstream effects on target genes, through the activation of the TGF $\beta$ and BMP2 osteogenic pathways [1,22], Figure 6(b)).

Our results also showed that LMP3 displays an inhibitory effect on KLF-4 gene expression. KLF genes encode a subclass of the zinc-finger family of transcription factors implicated in the regulation of cell growth and differentiation, acting on the cell cycle checkpoints $[21,30,31]$. Particularly, KLF4 is implicated in maintaining stem cells in an undifferentiated status and is able to mediate cancer cells proliferation, migration, and invasion $[30,31,41]$. The combination of KLF4 with other core-transcription factors (namely OCT4, SOX2, and c-MYC) define the "OSKM" gene network, widely used for reprogramming somatic cell and generate iPS [42-44]. We have recently demonstrated a role of KLF4 in defining the gene expression signature associated to MSC stemness maintenance [21]. Although a specific role for KLF4 in AFSC biology and homeostasis has not been yet demonstrated, the possibility of efficiently inducing iPS from amniotic fluid-derived cells through OSKM gene overexpression could reasonably corroborate this hypothesis $[40,45,46]$.

KLF4 was also found to be implicated in the TGF $\beta$ dependent regulation of smooth muscle cell differentiation; TGF $\beta$ downregulates KLF4, which, on its turn, represses

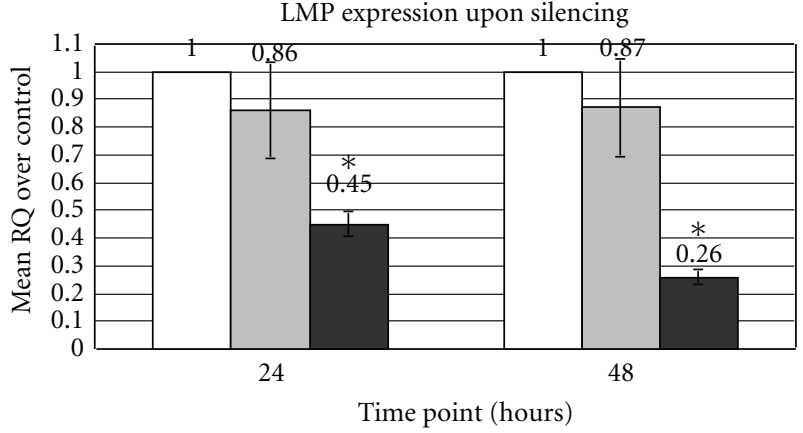

(a)

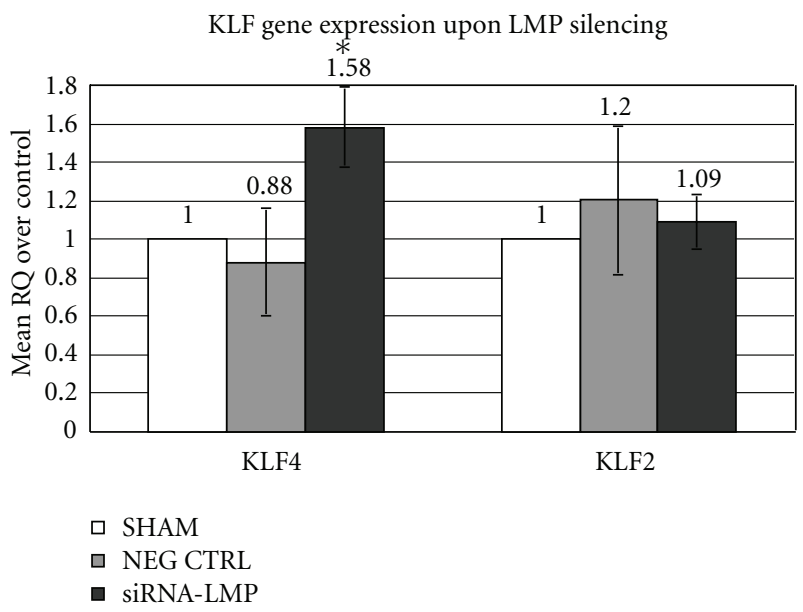

(b)

Figure 5: Gene expression analysis upon LMP silencing. The histogram represents the relative expression levels of LMP (24 and 48 hours following siRNA transfection, (a)), KLF2 and KLF4 (24 hours after LMP silencing, (b)). Values represent the mean of triplicate experiments for each test. SHAM: cells treated with transfection reagent alone; Neg Ctrl: cells transfected with AllStars Negative Control SiRNA; SiRNA-LMP: cells treated with SiRNALMP construct; RQ: relative quantity, calculated according to $2^{-\Delta \Delta C t}$ method; *: statistically significant $(P<0.01)$.

the TGF $\beta$-dependent increase in differentiation markers [47-49]. In the same cells, KLF4 was also found to induce the expression of the TGF $\beta$ receptor I and the activation of Smad2/3-p38 MAPK signaling, suggesting the existence of a feed-back loop implicated in the cell differentiation program [50]. Based on such evidences, the KLF4 downregulation described in this study could be considered among the basic molecular effects induced by LMP3 during the osteogenic commitment of AFSCs. Infact, upon LMP silencing, KLF4 expression transiently increased, suggesting that the osteogenic effects of LMP on AFSCs could be mediated, at least in part, by the inhibition of KLF4. We have previously shown that LMP3 induces the early transcriptional activation of TGF $\beta 1$ and related signaling pathway [22], which is known to underlie osteoblast differentiation of MSC [51]. Taken together, these data could suggest that LMP3-mediated osteogenic signaling implies the induction of TGF $\beta 1$ that, on its turn, may induce 


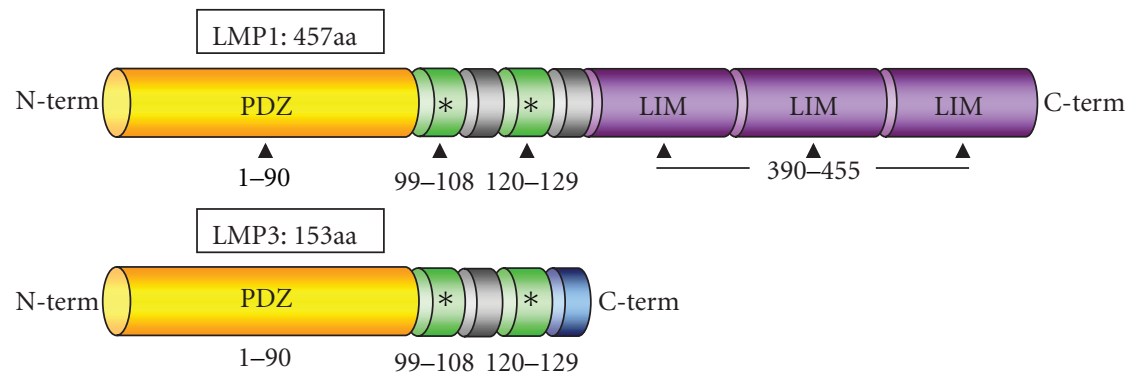

(a)

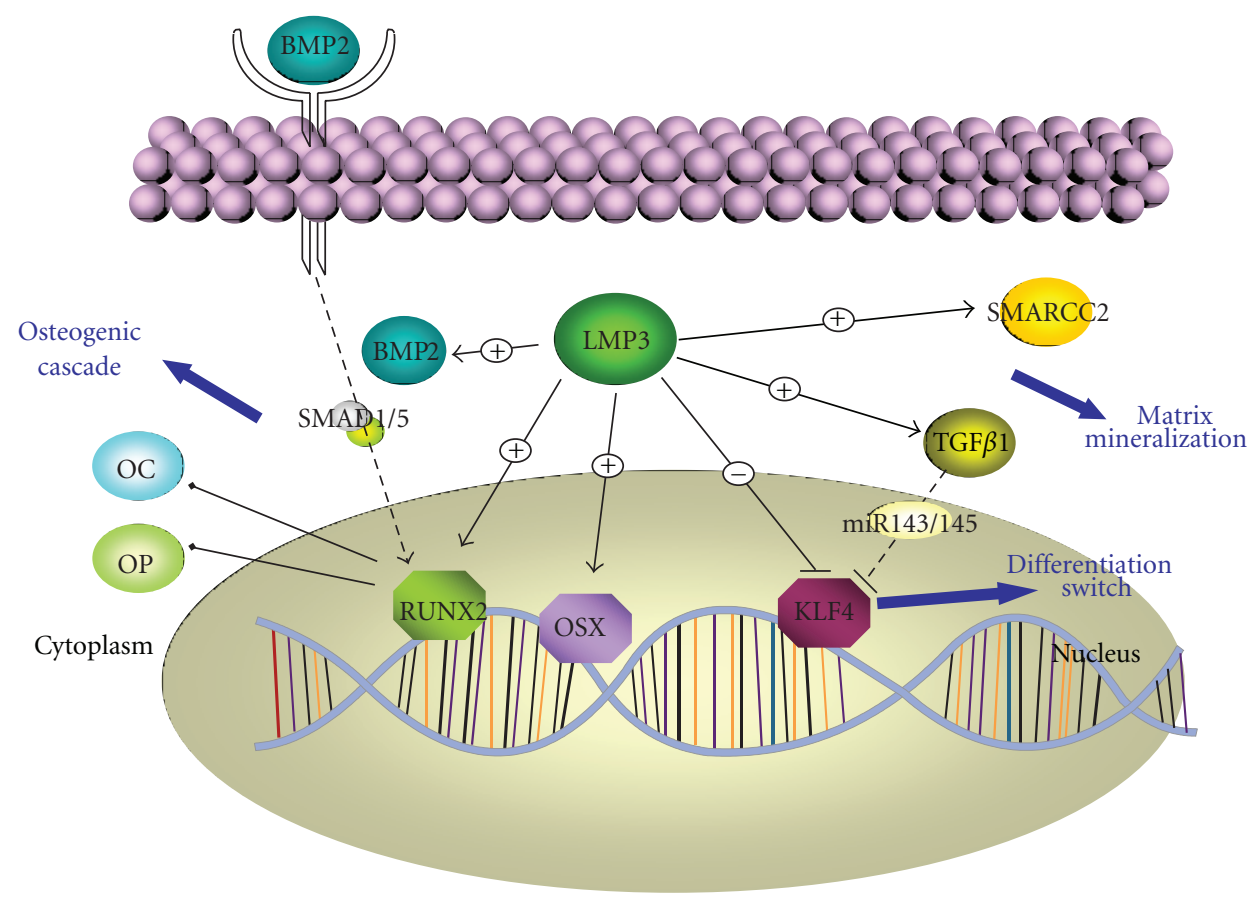

(b)

FIGURE 6: LMP domains and hypothetical signaling pathway.LMP1 and LMP3 are the osteogenic isoforms resulting from the alternative splicing of the PDLIM7 gene. (a) Both proteins share a conserved PDZ domain and a supposed osteogenic region which comprises two separate domains which interact with the SMURF1 WW2 domain (Sangadala et al, 2006). Three conserved LIM domains are present in the C-terminus of LMP1 while are absent in LMP3 due to its premature termination as a consequence of an out-of-frame insertion during splicing (see text for details). A scheme of the hypothetic molecular signaling induced by LMP3 in AFSC is proposed in (b) LMP3 induces the expression of the osteogenic transcription factors OSX and RUNX2, along with the osteogenic markers OC and OP. SMARCC2, involved in chromatin remodeling, is also a transcriptional target of LMP3, according to our results. LMP3 upregulates BMP2 that, on its turn, binds its surface receptor. This event induces the activating phosphorilation of SMADs that translocate to the nucleus to induce RUNX2, leading to the transcriptional induction of bone-specific genes mediating the osteogenic cascade. Conversely the KLF4 transcription factor is downregulated by LMP3. Also TGF $\beta$, induced by LMP3 in bone marrow-derived MSCs (Bernardini et al, 2010) represses KLF4 expression, by inducing the miR143-145 cluster (Davis-Dusenbery et al, 2011), which resulted unaffected by LMP3 overexpression. A + sign inducate positive regulation, a - sign indicate negative regulation on the arrows and lines; EC: extracellular compartment.

KLF4 downregulation. It was recently demonstrated that TGF $\beta$ induces KLF4 repression through the transcriptional activation of two microRNAs (miR-143/miR145), during the terminal differentiation of vascular smooth muscle cells [52]. No data so far described the possible involvement of the TGF $\beta$-miR143/145-KLF4 pathway in the molecular network underlying the osteogenic process. Our results indicated that mir143/145 were not involved in the LMP3-mediated KLF4 modulation, suggesting that an alternative pathway should be activated during the osteogenic commitment of AFSC.

Interestingly, no significant modulation of BMP2, RUNX2 and OSX gene expression occurred among the early molecular events induced by LMP3 overexpression in AFSC. This evidence is coherent with the early molecular profile 
observed in bone-marrow-derived MSC transduced with AdLMP3 [22]. This evidence may suggest that the activation of the TGF $\beta$ cascade is initiated by LMP through a BMP2independent mechanism, which may deserve further close examination.

The longer LMP isoform, LMP1, was recently described as a downstream target gene of TGF $\beta 1$, essential for the proliferation and differentiation of periodontal ligament progenitor cells [53]. These evidences may suggest the existence of a reciprocal feedback control between LMP molecules and TGF $\beta 1$ during cell replication and/or differentiation that may also implicate the transcriptional modulation of KLF4. Based on such observations, a clearer insight into the LMP3TGF interaction should be obtained in further studies, in order to delineate the correct molecular steps involved in the LMP-dependent osteogenic cascade.

Our results showed also that another KLF gene, KLF2, was apparently modulated during LMP3-induced osteogenic differentiation of AFSC, although it was not significantly modulated following LMP silencing. This suggested that KLF2 should not be directly regulated at the transcriptional level by LMP. KLF2 is one of the core transcription factors implicated in embryonic stem cells maintenance, self-renewal and pluripotency [54-56]. It has been recently demonstrated that KLF2 inhibits adipogenesis and monocyte differentiation [57-59] and governs specific developmental steps in different tissues [60, 61]. Although no clear evidence has suggested so far that KLF2 may affect osteogenic differentiation, it could be hypothesized that the KLF2 downregulation observed in LMP-overexpressing AFSCs could be a consequence of the cell differentiation process.

\section{Conclusions}

This study proposes some additional hints towards the functional characterization of LMP, which only recently emerged as an efficient osteogenic molecule. Based on the original data obtained in this study, the involvement of an alternative signaling, within the osteogenic cascade induced by LMP, could be assumed. This hypothesis may deserve ad hoc further investigations. Considering the easy retrieval of AFSCs and the lack of major invasiveness and ethical issues of the proposed isolation protocol, these results could provide a convincing proof-of-principle for the potential development of future autologous cell-based therapies based on these cells, to be employed for bone regeneration/healing purposes also in perinatal applications.

\section{Authors' Contributions}

M. Barba and F. Pirozzi contributed equally to this work.

\section{Acknowledgment}

The Authors thank Davide Bonvissuto and Enrico Guadagni for technical assistance. This work was supported by grant to WL by the Catholic University (linea D1-2011) and by the
FP7 EC grant OPHIS 2011-2014 - (FP7-NMP-2009-SMALL3-246373). E. Pola and W. Lattanzi share senior authorship.

\section{References}

[1] W. Lattanzi, C. Parrilla, A. Fetoni et al., "Ex vivo-transduced autologous skin fibroblasts expressing human Lim mineralization protein-3 efficiently form new bone in animal models," Gene Therapy, vol. 15, no. 19, pp. 1330-1343, 2008.

[2] C. Parrilla, W. Lattanzi, A. R. Fetoni, F. Bussu, E. Pola, and G. Paludetti, "Ex vivo gene therapy using autologous dermal fibroblasts expressing hLMP3 for rat mandibular bone regeneration," Head and Neck, vol. 32, no. 3, pp. 310-318, 2010.

[3] N. Saulnier, W. Lattanzi, M. A. Puglisi et al., "Mesenchymal stromal cells multipotency and plasticity: induction toward the hepatic lineage," European Review for Medical and Pharmacological Sciences, vol. 13, supplement 1, pp. 71-78, 2009.

[4] R. F. Pereira, K. W. Halford, M. D. O’Hara et al., "Cultured adherent cells from marrow can serve as long-lasting precursor cells for bone, cartilage, and lung in irradiated mice," Proceedings of the National Academy of Sciences of the United States of America, vol. 92, no. 11, pp. 4857-4861, 1995.

[5] M. F. Pittenger, A. M. Mackay, S. C. Beck et al., "Multilineage potential of adult human mesenchymal stem cells," Science, vol. 284, no. 5411, pp. 143-147, 1999.

[6] D. Woodbury, E. J. Schwarz, D. J. Prockop, and I. B. Black, "Adult rat and human bone marrow stromal cells differentiate into neurons," Journal of Neuroscience Research, vol. 61, no. 4, pp. 364-370, 2000.

[7] M. Dominici, K. Le Blanc, I. Mueller et al., "Minimal criteria for defining multipotent mesenchymal stromal cells. The International Society for Cellular Therapy position statement," Cytotherapy, vol. 8, no. 4, pp. 315-317, 2006.

[8] S. Y. Ong, H. Dai, and K. W. Leong, "Inducing hepatic differentiation of human mesenchymal stem cells in pellet culture," Biomaterials, vol. 27, no. 22, pp. 4087-4097, 2006.

[9] M. Hemberger, W. Yang, D. Natale et al., "Stem cells from fetal membranes-a workshop report," Placenta, vol. 29, pp. 17-19, 2008.

[10] K. I. Pappa and N. P. Anagnou, "Novel sources of fetal stem cells: where do they fit on the developmental continuum?" Regenerative Medicine, vol. 4, no. 3, pp. 423-433, 2009.

[11] P. De Coppi, G. Bartsch, M. M. Siddiqui et al., "Isolation of amniotic stem cell lines with potential for therapy," Nature Biotechnology, vol. 25, no. 1, pp. 100-106, 2007.

[12] P. S. In 't Anker, S. A. Scherjon, C. Kleijburg-van der Keur et al., "Amniotic fluid as a novel source of mesenchymal stem cells for therapeutic transplantation," Blood, vol. 102, no. 4, pp. 1548-1549, 2003.

[13] N. Sessarego, A. Parodi, M. Podestà et al., "Multipotent mesenchymal stromal cells from amniotic fluid: solid perspectives for clinical application," Haematologica, vol. 93, no. 3, pp. 339346, 2008.

[14] A. Poloni, G. Maurizi, L. Babini et al., "Human mesenchymal stem cells from chorionic villi and amniotic fluid are not susceptible to transformation after extensive in vitro expansion," Cell Transplantation, vol. 20, no. 5, pp. 643-654, 2011.

[15] J. Kim, Y. Lee, H. Kim et al., "Human amniotic fluid-derived stem cells have characteristics of multipotent stem cells," Cell Proliferation, vol. 40, no. 1, pp. 75-90, 2007.

[16] J. Hipp and A. Atala, "Sources of stem cells for regenerative medicine," Stem Cell Reviews, vol. 4, no. 1, pp. 3-11, 2008. 
[17] S. W. S. Shaw, A. L. David, and P. De Coppi, "Clinical applications of prenatal and postnatal therapy using stem cells retrieved from amniotic fluid," Current Opinion in Obstetrics and Gynecology, vol. 23, no. 2, pp. 109-116, 2011.

[18] E. Y. L. Waese, R. R. Kandel, and W. L. Stanford, "Application of stem cells in bone repair," Skeletal Radiology, vol. 37, no. 7, pp. 601-608, 2008.

[19] H. Sun, K. Feng, J. Hu, S. Soker, A. Atala, and P. X. Ma, "Osteogenic differentiation of human amniotic fluid-derived stem cells induced by bone morphogenetic protein-7 and enhanced by nanofibrous scaffolds," Biomaterials, vol. 31, no. 6, pp. 1133-1139, 2010.

[20] J. S. Park, H. N. Yang, D. G. Woo, S. Y. Jeon, and K. H. Park, "The promotion of chondrogenesis, osteogenesis, and adipogenesis of human mesenchymal stem cells by multiple growth factors incorporated into nanosphere-coated microspheres," Biomaterials, vol. 32, no. 1, pp. 28-38, 2011.

[21] N. Saulnier, M. A. Puglisi, W. Lattanzi et al., "Gene profiling of bone marrow- and adipose tissue-derived stromal cells: a key role of Kruppel-like factor 4 in cell fate regulation," Cytotherapy, vol. 13, no. 3, pp. 329-340, 2011.

[22] C. Bernardini, N. Saulnier, C. Parrilla et al., "Early transcriptional events during osteogenic differentiation of human bone marrow stromal cells induced by Lim mineralization protein 3," Gene Expression, vol. 15, no. 1, pp. 27-42, 2010.

[23] E. Pola, W. Gao, Y. Zhou et al., "Efficient bone formation by gene transfer of human LIM mineralization protein-3," Gene Therapy, vol. 11, no. 8, pp. 683-693, 2004.

[24] S. D. Boden, Y. Liu, G. A. Hair et al., "LMP-1, a LIMdomain protein, mediates BMP-6 effects on bone formation," Endocrinology, vol. 139, no. 12, pp. 5125-5134, 1998.

[25] S. D. Boden, L. Titus, G. Hair et al., "1998 Volvo award winner in basic sciences studies: Lumbar spine fusion by local gene therapy with a cDNA encoding a novel osteoinductive protein (LMP-1)," Spine, vol. 23, no. 23, pp. 2486-2492, 1998.

[26] Y. Liu, G. A. Hair, S. D. Boden, M. Viggeswarapu, and L. Titus, "Overexpressed LIM mineralization proteins do not require LIM domains to induce bone," Journal of Bone and Mineral Research, vol. 17, no. 3, pp. 406-414, 2002.

[27] S. Sangadala, S. D. Boden, M. Viggeswarapu, Y. Liu, and L. Titus, "LIM mineralization protein-1 potentiates bone morphogenetic protein responsiveness via a novel interaction with Smurf1 resulting in decreased ubiquitination of smads," Journal of Biological Chemistry, vol. 281, no. 25, pp. 1721217219, 2006.

[28] M. S. Tsai, J. L. Lee, Y. J. Chang, and S. M. Hwang, "Isolation of human multipotent mesenchymal stem cells from secondtrimester amniotic fluid using a novel two-stage culture protocol," Human Reproduction, vol. 19, no. 6, pp. 1450-1456, 2004.

[29] D. W. Young, J. Pratap, A. Javed et al., "SWI/SNF chromatin remodeling complex is obligatory for BMP2-induced, Runx2dependent skeletal gene expression that controls osteoblast differentiation," Journal of Cellular Biochemistry, vol. 94, no. 4, pp. 720-730, 2005.

[30] Y. Li, J. McClintick, L. Zhong, H. J. Edenberg, M. C. Yoder, and R. J. Chan, "Murine embryonic stem cell differentiation is promoted by SOCS-3 and inhibited by the zinc finger transcription factor Klf4," Blood, vol. 105, no. 2, pp. 635-637, 2005.

[31] Y. Natanake, N. Fukui, Y. Iwamatsu et al., "Klf4 cooperates with Oct3/4 and Sox2 to activate the Lefty1 core promoter in embryonic stem cells," Molecular and Cellular Biology, vol. 26, no. 20 , pp. $7772-7782,2006$.
[32] K. J. Livack and T. D. Schmittgen, "Analysis of relative gene expression data using real-time quantitative PCR and the 2$\Delta \Delta$ CT method," Methods, vol. 25, no. 4, pp. 402-408, 2001.

[33] M. Viggeswarapu, S. D. Boden, Y. Liu et al., "Adenoviral delivery of LIM mineralization protein-1 induces new-bone formation in vitro and in vivo," Journal of Bone and Joint Surgery. Series A, vol. 83, no. 3, pp. 364-376, 2001.

[34] H. S. Kim, M. Viggeswarapu, S. D. Boden et al., "Overcoming the immune response to permit ex vivo gene therapy for spine fusion with human type 5 adenoviral delivery of the LIM mineralization protein-1 cDNA," Spine, vol. 28, no. 3, pp. 219226, 2003.

[35] S. T. Yoon, J. S. Park, K. S. Kim et al., "ISSLS prize winner: LMP-1 upregulates intervertebral disc cell production of proteoglycans and BMPs in vitro and in vivo," Spine, vol. 29, no. 23, pp. 2603-2611, 2004.

[36] Q. Fei, S. D. Boden, S. Sangadala, M. Viggeswarapu, Y. Liu, and L. Titus, "Truncated human LMP-1 triggers differentiation of C2C 12 cells to an osteoblastic phenotype in vitro," Acta Biochimica et Biophysica Sinica, vol. 39, no. 9, pp. 693-700, 2007.

[37] C. A. Strohbach, C. H. Rundle, J. E. Wergedal et al., "LMP1 retroviral gene therapy influences osteoblast differentiation and fracture repair: a preliminary study," Calcified Tissue International, vol. 83, no. 3, pp. 202-211, 2008.

[38] X. Wang, F. Cui, V. Madhu, A. S. Dighe, G. Balian, and Q. Cui, "Combined VEGF and LMP-1 delivery enhances osteoprogenitor cell differentiation and ectopic bone formation," Growth Factors, vol. 29, no. 1, pp. 36-48, 2011.

[39] A. Minamide, S. D. Boden, M. Viggeswarapu, G. A. Hair, C. Oliver, and L. Titus, "Mechanism of bone formation with gene transfer of the cDNA encoding for the intracellular protein LMP-1," Journal of Bone and Joint Surgery. Series A, vol. 85, no. 6, pp. 1030-1039, 2003.

[40] E. Galende, I. Karakikes, L. Edelmann et al., "Amniotic fluid cells are more efficiently reprogrammed to pluripotency than adult cells," Cellular Reprogramming, vol. 12, no. 2, pp. 117$125,2010$.

[41] F. Yu, J. Li, H. Chen et al., "Kruppel-like factor 4 (KLF4) is required for maintenance of breast cancer stem cells and for cell migration and invasion," Oncogene, vol. 30, no. 18, pp. 2161-2172, 2011.

[42] K. Takahashi, K. Tanabe, M. Ohnuki et al., "Induction of pluripotent stem cells from adult human fibroblasts by defined factors," Cell, vol. 131, no. 5, pp. 861-872, 2007.

[43] Z. Lin, P. Perez, D. Lei, J. Xu, X. Gao, and J. Bao, "Twophase analysis of molecular pathways underlying induced pluripotent stem cell induction," Stem Cells, vol. 29, no. 12, pp. 1963-1974, 2011.

[44] N. Mah, Y. Wang, M.-C. Liao et al., "Molecular insights into reprogramming-initiation events mediated by the OSKM gene regulatory network," PLoS One, vol. 6, no. 8, Article ID e24351, 2011.

[45] C. Li, J. Zhou, G. Shi et al., "Pluripotency can be rapidly and efficiently induced in human amniotic fluid-derived cells," Human Molecular Genetics, vol. 18, no. 22, pp. 4340-4349, 2009.

[46] H. E. Lu, M. S. Tsai, Y. C. Yang et al., "Selection of alkaline phosphatase-positive induced pluripotent stem cells from human amniotic fluid-derived cells by feeder-free system," Experimental Cell Research, vol. 317, no. 13, pp. 1895-1903, 2011.

[47] K. E. King, V. P. Iyemere, P. L. Weissberg, and C. M. Shanahan, "Krüppel-like factor 4 (KLF4/GKLF) is a target of bone 
morphogenetic proteins and transforming growth factor $\beta 1$ in the regulation of vascular smooth muscle cell phenotype," Journal of Biological Chemistry, vol. 278, no. 13, pp. 1166111669, 2003.

[48] K. Kawai-Kowase, T. Ohshima, H. Matsui et al., "PIAS1 mediates TGFbeta-induced SM alpha-actin gene expression through inhibition of KLF4 function-expression by protein sumoylation," Arteriosclerosis, Thrombosis, and Vascular Biology, vol. 29, no. 1, pp. 99-106, 2009.

[49] P. J. Adam, C. P. Regan, M. B. Hautmann, and G. K. Owens, "Positive- and negative-acting Kruppel-like transcription factors bind a transforming growth factor beta control element required for expression of the smooth muscle cell differentiation marker SM22alpha in vivo," The Journal of Biological Chemistry, vol. 275, no. 48, pp. 37798-37806, 2000.

[50] H. X. Li, M. Han, and M. Bernier, "Krüppel-like factor 4 promotes differentiation by transforming growth factor-beta receptor-mediated Smad and p38 MAPK signaling in vascular smooth muscle cells," The Journal of Biological Chemistry, vol. 285, no. 23, pp. 17846-17856, 2010.

[51] B. Kulterer, G. Friedl, A. Jandrositz et al., "Gene expression profiling of human mesenchymal stem cells derived from bone marrow during expansion and osteoblast differentiation," BMC Genomics, vol. 8, article no. 70, 2007.

[52] B. N. Davis-Dusenbery, M. C. Chan, K. E. Reno et al., "Downregulation of Krüppel-like Factor-4 (KLF4) by microRNA$143 / 145$ is critical for modulation of vascular smooth muscle cell phenotype by transforming growth factor- $\beta$ and bone morphogenetic protein 4," The Journal of Biological Chemistry, vol. 286, no. 32, pp. 28097-28110, 2011.

[53] Z. Lin, V. P. Navarro, K. M. Kempeinen et al., "LMP1 regulates periodontal ligament progenitor cell proliferation and differentiation," Bone, vol. 47, no. 1, pp. 55-64, 2010.

[54] J. Jiang, Y. S. Chan, Y. H. Loh et al., "A core Klf circuitry regulates self-renewal of embryonic stem cells," Nature Cell Biology, vol. 10, no. 3, pp. 353-360, 2008.

[55] J. Hall, G. Guo, J. Wray et al., "Oct4 and LIF/Stat3 additively induce krüppel factors to sustain embryonic stem cell selfrenewal," Cell Stem Cell, vol. 5, no. 6, pp. 597-609, 2009.

[56] G. Ficz, M. R. Branco, S. Seisenberger et al., "Dynamic regulation of 5-hydroxymethylcytosine in mouse ES cells and during differentiation," Nature, vol. 473, no. 7347, pp. 398402, 2011.

[57] J. Lee, J. Lee, E. Jung et al., "Ultraviolet A regulates adipogenic differentiation of human adipose tissue-derived mesenchymal stem cells via up-regulation of Kruppel-like factor 2," Journal of Biological Chemistry, vol. 285, no. 42, pp. 32647-32656, 2010.

[58] D. C. Berry, D. DeSantis, H. Soltanian, C. M. Croniger, and N. Noy, "Retinoic acid upregulates preadipocyte genes to block adipogenesis and suppress diet-induced obesity," Diabetes, vol. 61, no. 5, pp. 1112-1121, 2012.

[59] M. Das, J. Lu, M. Joseph et al., "Kruppel-like factor 2 (KLF2) regulates monocyte differentiation and functions in $\mathrm{mBSA}$ and IL-1 $\beta$-induced arthritis," Current Molecular Medicine, vol. 12, no. 2, pp. 113-125, 2012.

[60] S. M. Meadows, M. C. Salanga, and P. A. Krieg, "Krüppellike factor 2 cooperates with the ETS family protein ERG to activate Flk1 expression during vascular development," Development, vol. 136, no. 7, pp. 1115-1125, 2009.

[61] P. Xie, Y. Tang, S. Shen et al., "Smurf1 ubiquitin ligase targets Kruppel-like factor KLF2 for ubiquitination and degradation in human lung cancer H1299 cells," Biochemical and Biophysical Research Communications, vol. 407, no. 1, pp. 254-259, 2011. 

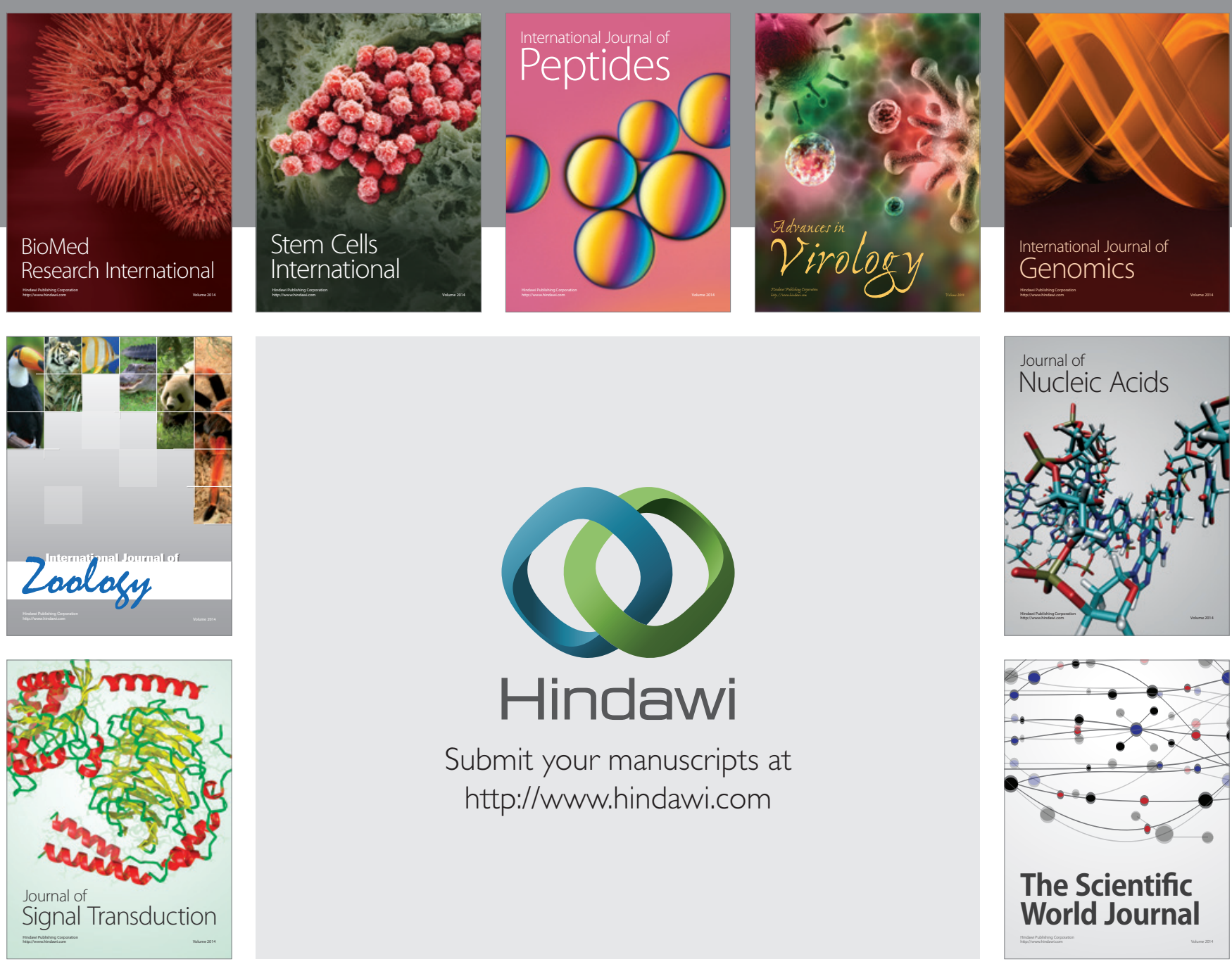

Submit your manuscripts at

http://www.hindawi.com
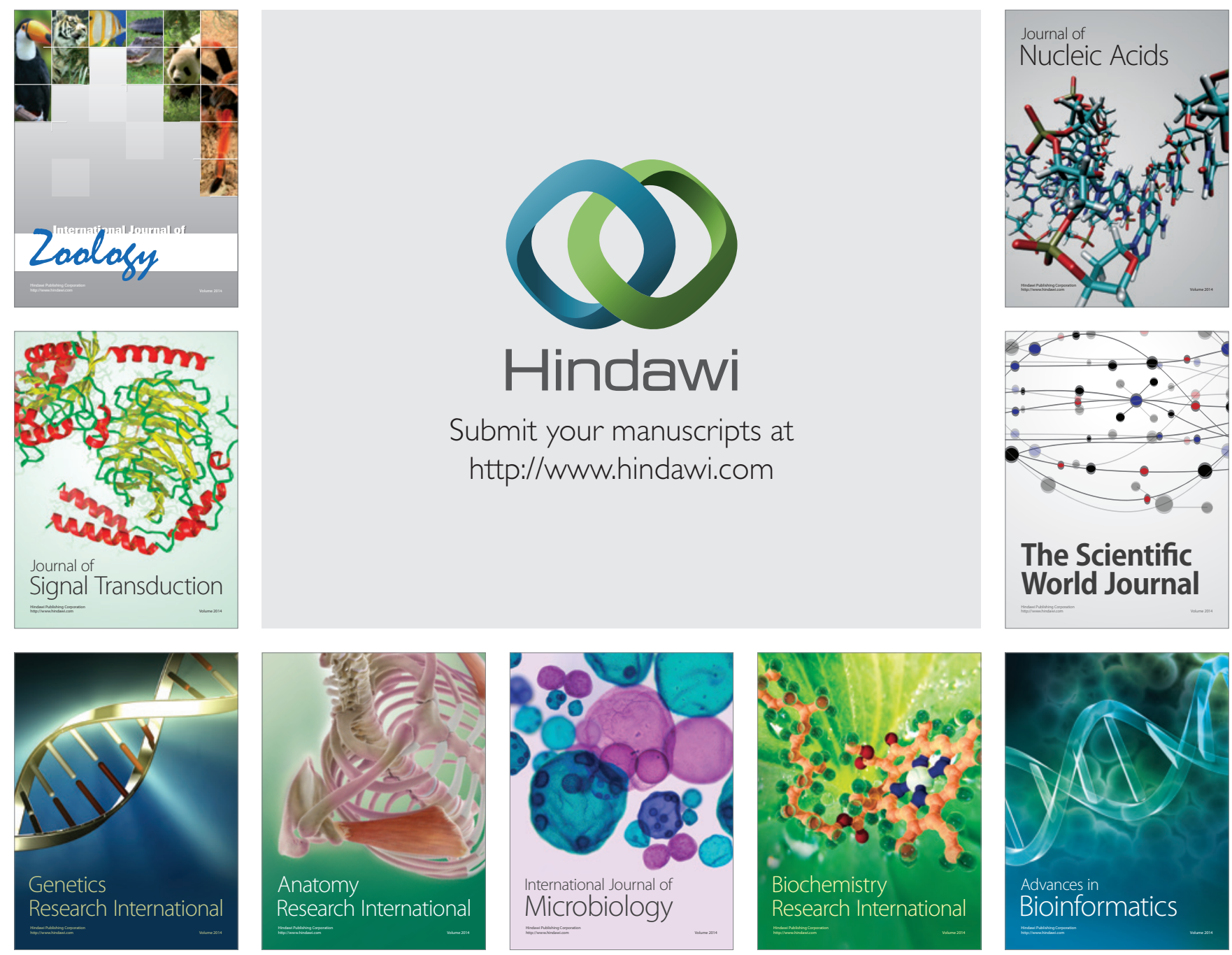

The Scientific World Journal
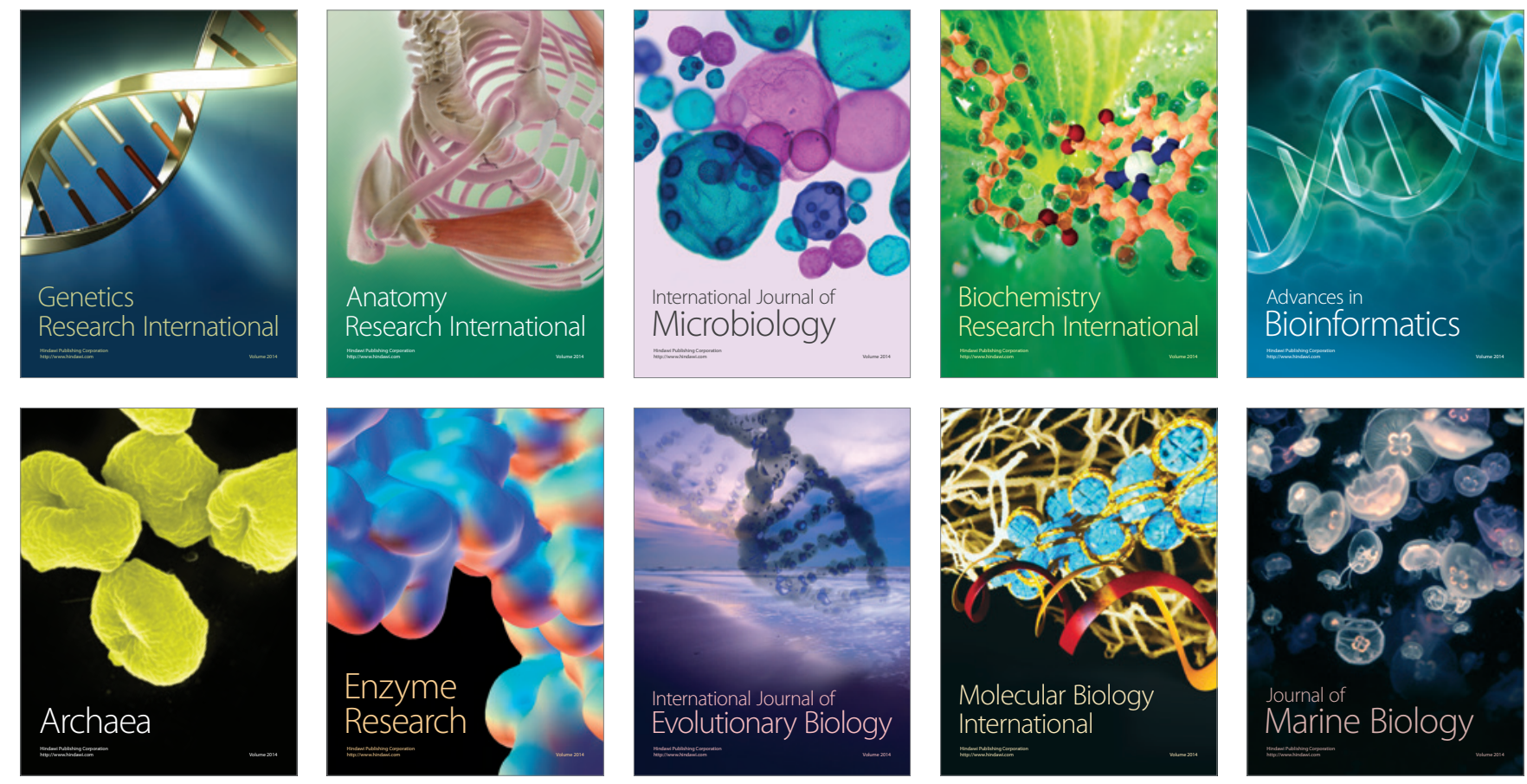